\title{
The Influence of COVID-19 Lockdown Restrictions on Perceived Nutrition Habits in Rugby Union Players
}

\author{
Charlie Roberts $^{1 *}$, Nicholas Gill ${ }^{1,2}$ and Stacy Sims ${ }^{1}$ \\ ${ }^{1}$ Te Huataki Waiora School of Health, University of Waikato, Hamilton, New Zealand, ${ }^{2}$ New Zealand Rugby Union, Wellington, \\ New Zealand
}

The global outbreak of COVID-19 has led to governments and local authorities implementing nationwide lockdowns in an attempt to encourage social distancing and minimize the spread of the virus. Only essential businesses have been able to remain open, with non-essential businesses and activities either closing or restricting services. With no group training sessions allowed, canceled matches, an inability to work and the closure of eating establishments, Rugby Union players have experienced disruption to their daily lives. Two surveys were distributed among Rugby Union athletes to explore (1) the influence of COVID-19 lockdown restrictions on Rugby Union players' nutrition and training habits and (2) how nutrition habits in New Zealand Rugby Union players change after lockdown restrictions were lifted. In total, 258

\section{OPEN ACCESS}

Edited by:

Simon Rosenbaum,

University of New South

Wales, Australia

Reviewed by:

Kevin Till,

Leeds Beckett University, United Kingdom

Joelle Leonie Flueck,

Swiss Paraplegic Center, Switzerland

*Correspondence:

Charlie Roberts

charlie.jon.roberts@gmail.com

Specialty section:

This article was submitted to

Sport and Exercise Nutrition,

a section of the journal

Frontiers in Nutrition

Received: 31 July 2020 Accepted: 18 September 2020

Published: 26 October 2020

Citation:

Roberts C, Gill N and Sims S (2020)

The Influence of COVID-19 Lockdown

Restrictions on Perceived Nutrition

Habits in Rugby Union Players.

Front. Nutr. 7:589737.

doi: 10.3389/fnut.2020.589737 respondents completed Survey 1 (84.1\% male, 26.4\% professional/semi-professional). Of the respondents, $58 \%$ indicated they lived with family during lockdown. Total food intake was reported to be higher in $36 \%$ of respondents. Fruit and vegetable intake was lower (17\%) and packaged/convenience food intake higher (26\%) in a minority of respondents. In total, 106 respondents completed Survey 2 (84.9\% male, 34.0\% professional/semi-professional). Of the respondents, $72 \%$ prepared and $67 \%$ purchased their own food. Less than half of respondents consumed high-protein food more than twice daily either during or following lockdown. Compared to during lockdown, motivation to train and exercise was greater in 58\% of respondents following lockdown. Dieticians and nutritionists within clubs provided most of the nutrition knowledge to athletes however other unreliable sources were identified, such as social media and family members. The ongoing pandemic has presented significant challenges for athletes concerning training and nutrition habits and the current study provides some insight into these. Coaches and performance staff should ensure athletes receive appropriate nutritional and training support whilst being aware of the unique demands the individuals' may face.

Keywords: COVID-19, Rugby Union, athlete, nutrition habits, training, social distancing measures

\section{INTRODUCTION}

COVID-19 is a novel strain of coronavirus that can cause severe acute respiratory distress. It is spread via droplets generated by sneezing, coughing or talking and is therefore easily transmitted between humans. COVID-19 was declared a global pandemic by the World Health Organization on 11th March 2020 (1) and measures have been implemented by governments and local authorities to 
minimize the spread of the virus. These measures include social distancing (aiming to keep people from different households separate unless required) and rigid hygiene protocols (wearing masks when out in public, regular washing and sanitizing of hands and surfaces). The implementation of these guidelines has since resulted in global travel bans and restrictions on engaging in activities deemed "non-essential."

In New Zealand, Alert Level Four lockdown restrictions were enforced between 25th March 2020 and 27th April 2020, with businesses that aren't deemed essential (e.g., supermarkets, pharmacies) forced to close. Between 27th April 2020 and 13th May 2020, Alert Level Three was enforced in New Zealand which brought around some changes (e.g., fast food establishments could operate a take-away service only) however gatherings of more than 10 people from different households was not permitted. Following the reduction to Alert Level Two on 13th May 2020, which allowed for most restaurants, businesses and activities to resume provided appropriate contact tracing, social distancing and hygiene rules were enforced, most people were able to resume habitual activities. On 8th June 2020, Alert Level One meant no restrictions were enforced in New Zealand with the exception of border entry being strictly controlled to allow only citizens and permanent residents entry following a 2 week quarantine.

Organizations and individuals involved in sport and physical activity have experienced significant restrictions due the COVID19 social distancing measures. Sporting events at all levels, from schools and clubs to large international events such as the 2020 Olympic Games, have been canceled or postponed. This has resulted in organized training sessions being deemed non-essential with many athletes forced to reduce their training volume drastically. Additionally, stresses related to illness and health, economic uncertainty and prolonged social isolation may lead to unfavorable or additional mental health outcomes in athletes $(2,3)$.

Engaging in regular physical activity has been encouraged (4) although social distancing guidelines may affect team and contact sports. Although some athletes are able to continue training and preparing for competition, sports requiring physical contact face additional issues surrounding training preparation. Rugby Union is a combative sport and the high incidence of players engaging in physical contact in the form of tackles, rucks, mauls, and scrums (5) thus social distancing guidelines have particular relevance to collision-based team sport athletes. Rugby Union athletes have been unable to participate in sport-specific activity during lockdown restrictions, which vary from country to country. Strict lockdown measures restricting access to habitual training environments and contact with other players mean coaches and practitioners are faced with challenges regarding developing or maintaining essential attributes required by Rugby Union athletes (lean mass, strength, power, speed, agility, sportspecific skills, decision-making ability) (6).

Not only have training and competition been affected by COVID-19, lockdown restrictions are likely to have influenced athletes' perceived nutrition habits. Nutrition habits can be defined as "the habitual decisions of individuals or group of people regarding what foods they eat" (7). For example, habitual eating patterns will have changed significantly with the closure of eating establishments and food delivery services. Furthermore, stressors as a direct result of COVID-19 lockdown restrictions may result in unfavorable food choices (8). Additional challenges associated with monitoring nutrient intake during lockdown are likely to be encountered by clubs due to less direct contact with nutrition professionals. It is vital athletes receive the appropriate nutritional support during lockdown as an abrupt return to training and play once restrictions are lifted may result in increased risk of injury (9) and it is likely good dietary habits may alleviate this $(10,11)$.

Numerous surveys have been distributed across different populations and countries to identify the effect of COVID-19 lockdown measures on dietary patterns $(12,13)$ however no data has been reported in Rugby Union athletes. The purpose of this study is to explore (1) the influence of COVID-19 lockdown restrictions on Rugby Union players' nutrition and training habits and (2) how nutrition habits in New Zealand Rugby Union players change after lockdown restrictions were lifted.

\section{METHODS}

The research instruments consisted of two surveys administered via an online survey-hosting website (Survey Monkey, Palo Alto, CA, USA). Within human ethics research regulations, this study was deemed to be low risk. All participants granted informed consent prior to commencing any of the surveys.

The first survey, entitled "Nutrition \& Training Habits in Rugby Union Players - COVID-19 Lockdown" was administered from April 19th 2020 to May 22nd 2020, during which full lockdown restrictions were enforced in New Zealand and many countries globally. Initially, management staff and/or coaching staff from Rugby Union teams located in New Zealand, Australia and the United Kingdom were approached via e-mail. The purpose of the survey was explained, and management staff were asked to distribute the survey web link to their players. The survey consisted of 30 questions organized into three sectionsgeneral information, nutrition and training.

The second survey, entitled "Post-Lockdown Nutrition \& Training Habits in Rugby Union Players" was administered from 2nd June 2020 to 2nd July 2020. The survey consisted of 28 questions. Management staff from Rugby Union teams in New Zealand were approached via e-mail due to the complete relaxation of lockdown restrictions. An information page was presented prior to the survey and consent was gained via a consent statement and check box.

Descriptive analysis of results are presented as percentages (\%) of responses.

\section{RESULTS}

For a full breakdown of Survey 1 and 2 questions and responses, please see Supplementary Materials. Relevant results will be discussed in the subsequent sections.

\section{Survey 1}

Relevant results will be discussed in this section. 
In total, of the 314 survey link clicks, 258 respondents (82\% total) completed Survey 1. Demographics for the survey respondents are presented in Table 1. The respondents were $18-25$ years of age $(59.7 \%)$, male $(84.1 \%)$ and living in New Zealand (92.2\%). Only $26.3 \%$ of respondents reported playing at either a semi-professional or a professional level, with amateur players representing competitive club level or academy teams. Living with family accounted for $58.5 \%$ of responses. During lockdown, $39.2 \%$ of respondents indicated their motivation to train was lower than usual, with $32.6 \%$ reporting no change in motivation levels and $28.3 \%$ stating motivation to train had increased during lockdown.

Most respondents reported consuming breakfast daily (63.2\%), eating 2-3 meals (67.1\%) and $1-2$ snacks (63.6\%) per day. Respondents reported that a family member was most likely to purchase their food during lockdown (42.6\%). Whilst $44.6 \%$ of respondents prepared their own food and meals, family members (23.6\%) and a combination of people (23.3\%) (the respondent and others in the household) were also involved in the food/meal preparation process.

Total food intake was reported to be greater during lockdown in $35.7 \%$ of respondents. During lockdown, $16.7 \%$ of respondents' fruit and vegetable intake was lower than before lockdown, with the remainder indicating their intake was either the same or higher than before the restrictions. Packaged/convenience food intake was lower in lockdown for $41.9 \%$ of participants.

Nutrition knowledge in respondents was primarily from a dietician or nutritionist associated with the club (61.6\%) however coaching staff $(25.2 \%)$, teammates (27.1\%), family members $(30.6 \%)$, the internet $(31.1 \%)$ and social media also contributed. When asked about the frequency of consumption of complete high-protein foods, $49.2 \%$ of respondents reported greater than two daily feedings. Respondents who consumed no dietary supplements during lockdown consisted of $53.3 \%$ of total responses.

\section{Survey 2}

In total, of the 112 survey link clicks, 106 respondents ( $95 \%$ total) completed Survey 2. Demographics for the survey respondents are displayed in Table 1. Respondents were 18-25 years old (66.0\%) and male (84.9\%). In total, $34.0 \%$ of respondents perform at a semi-professional or professional level. Most respondents reported living with family $(33.0 \%)$ or flatting in shared accommodation $(31.1 \%)$. Motivation to train and exercise was greater in $59.5 \%$ of respondents compared to during lockdown.

As with Survey 1, most respondents reported daily breakfast consumption (72.6\%), eating 2-3 meals (51.9\%) and 1-2 snacks (71.7\%) per day. The vast majority of respondents purchased (67.0\%) and prepared their own food and meals (71.0\%). Eating out at takeaways, cafes and restaurants at least once per week was reported in $45.3 \%$ of respondents, with $8.4 \%$ indicating their frequency of eating out was $\geq 3$ times weekly.

Dieticians or nutritionists associated with the club provided $68.9 \%$ of respondents nutrition knowledge, with coaching staff $(26.4 \%)$, teammates $(33.0 \%)$, family members, the internet $(31.1 \%)$ and social media $(22.6 \%)$ again contributing.
Consumption of $\leq 1$ complete, high-protein food source daily was reported by $50.9 \%$ of respondents. No supplement use was reported in $32.1 \%$ of respondents.

\section{Comparison Between Survey 1 and Survey} 2

To compare results between surveys, responses from athletes located in countries other than New Zealand were filtered out. Relevant results are displayed in Figures 1-8 as comparisons between results presented by amateur players and semiprofessional/professional players.

The relaxation of lockdown restrictions caused a change in living situations. Living with family accounted for 58.5\% of responses during lockdown compared to $33.0 \%$ following lockdown, and flatting in shared accommodation accounted for $10.1 \%$ of responses during lockdown and $31.13 \%$ after lockdown (Figure 3). Following lockdown, the responses indicate a shift to athletes becoming more self-reliant and both purchasing $(67.0 \%$ compared to $38.0 \%$, Figure 2$)$ and preparing (71.7\% compared to $44.6 \%$, Figure 1) their own food and meals. Post-lockdown, respondents reported a much higher motivation to train (57.9\%) compared to during lockdown (28.7\%) (Figure 4).

Most respondents reported no change in nutrition habits from during lockdown to post-lockdown (50.9\%) whilst 35.9\% indicated that their nutrition habits were better (Figure 6). Additionally, total food (44.3\%, Figure 5), fruit and vegetable (53.8\%, Figure 7$)$ and packaged/convenience food $(45.3 \%$, Figure 8) was reported to be the same following lockdown.

\section{DISCUSSION}

The purpose of this study was to explore (1) the influence of COVID-19 lockdown restrictions on Rugby Union players' nutrition and training habits and (2) how nutrition habits in New Zealand Rugby Union players were affected by the relaxation of lockdown restrictions. Nationwide lockdowns are unprecedented and as such no data is currently available describing how the combinations of (1) disruption to daily life (2) inability to train and eat habitually and (3) stress due to the global pandemic may have influenced these factors in athletes.

\section{During Lockdown}

The majority of responses indicated that their food intake during lockdown either remained the same or increased. Whilst the long-term implication of COVID-19 lockdown restrictions on body composition have not been reported, athletes would be wise to reduce total energy intake to reflect the reduction of physical activity (14). Many respondents engaged in regular training sessions $(89.4 \%$ reported completing $\geq 3$ sessions per week) however the shift from habitual practices likely resulted in a large reduction in daily energy expenditure. Factors influencing energy expenditure during lockdown in athletes include a requirement to perform training sessions either at home or in local outdoor areas such as parks, a lack of equipment (free weights, machines) and no competition between teammates being present. These factors mean minimal rugbyspecific training sessions were performed. 
TABLE 1 | Demographic information for survey 1 (during lockdown) and survey 2 (after lockdown).

\begin{tabular}{|c|c|c|c|}
\hline & & During Lockdown & After Lockdown \\
\hline & $18-25$ years & 59.7 & 66.0 \\
\hline & $26-35$ years & 21.3 & 16.0 \\
\hline & $>35$ years & 4.7 & 0.00 \\
\hline \multirow{2}{*}{ Sex } & Female & 15.1 & 15.1 \\
\hline & Prefer not to say & 0.8 & 0.00 \\
\hline \multirow[t]{3}{*}{ Country of Residence } & New Zealand & 92.2 & 100.0 \\
\hline & Australia & 3.5 & 0.0 \\
\hline & United Kingdom & 4.3 & 0.0 \\
\hline \multirow{4}{*}{$\begin{array}{l}\text { How would you describe your living situation before } \\
\text { lockdown restrictions were enforced? }\end{array}$} & Alone & 2.3 & - \\
\hline & With friends & 4.7 & - \\
\hline & Flatting & 26.4 & - \\
\hline & Other & 7.0 & - \\
\hline \multirow{7}{*}{$\begin{array}{l}\text { How would you describe your current living } \\
\text { situation? }\end{array}$} & Alone & 1.9 & 2.8 \\
\hline & With a partner & 13.2 & 17.9 \\
\hline & With family (parents, siblings, etc.) & 58.5 & 33.0 \\
\hline & With family (partner, children, etc.) & 9.7 & 2.8 \\
\hline & With friends & 3.9 & 7.6 \\
\hline & Flatting & 10.1 & 31.1 \\
\hline & Other & 2.7 & 4.7 \\
\hline
\end{tabular}

The temporary closure of restaurants, fast food outlets, cafes and bars may have resulted in better food choices in athletes. Most respondents indicated that fruit and vegetable intake during lockdown either remained the same or increased from prelockdown. Additionally, packaged and convenience food intake either remained the same or was lower during lockdown. These contrast with general population surveys distributed during COVID-19 lockdown restrictions, with one third of 1097 Polish respondents not consuming fresh fruit or vegetables on a daily basis (13). In a global survey distributed through 35 research institutions, respondents reported eating in an unhealthier pattern along with consuming more snacks and meals when COVID-19 lockdown restrictions were enforced (15).

Ingesting adequate protein (1.2-2.0 g.kg.d) (16) is an important factor in ensuring lean mass retention. When inadequate dietary protein is consumed, negative protein balance can result in muscle protein catabolism, adversely affecting muscle mass and function (17). In Survey 1, only $43.9 \%$ of respondents reported consuming a whole-food, high biological value protein source more than twice daily, which may not be optimal for retaining lean mass during a prolonged lockdown period.

During lockdown, most of respondents implied they consumed no dietary supplements. High heterogeneity exists in the evidence-base surrounding dietary supplement use among athletes and prevalence recorded between studies is variable (18). Additionally, consultation with a nutrition professional should occur to consider the benefits and risks involved with consuming certain supplements (19). Nonetheless, consumption of certain supplements may be beneficial for athletes provided training, nutrition and recovery habits are sound (20). Due to the additional stressors of the lockdown, supplement use may not have been a priority for athletes.

Protein supplementation is a beneficial strategy for athletes to reach daily requirements (21). Whilst protein intake is recommended to primarily come from whole foods, whey and casein are of a high quality, and consumption is considered safe and convenient (16). With most survey respondents reporting consuming a high-protein food source $\leq$ once 

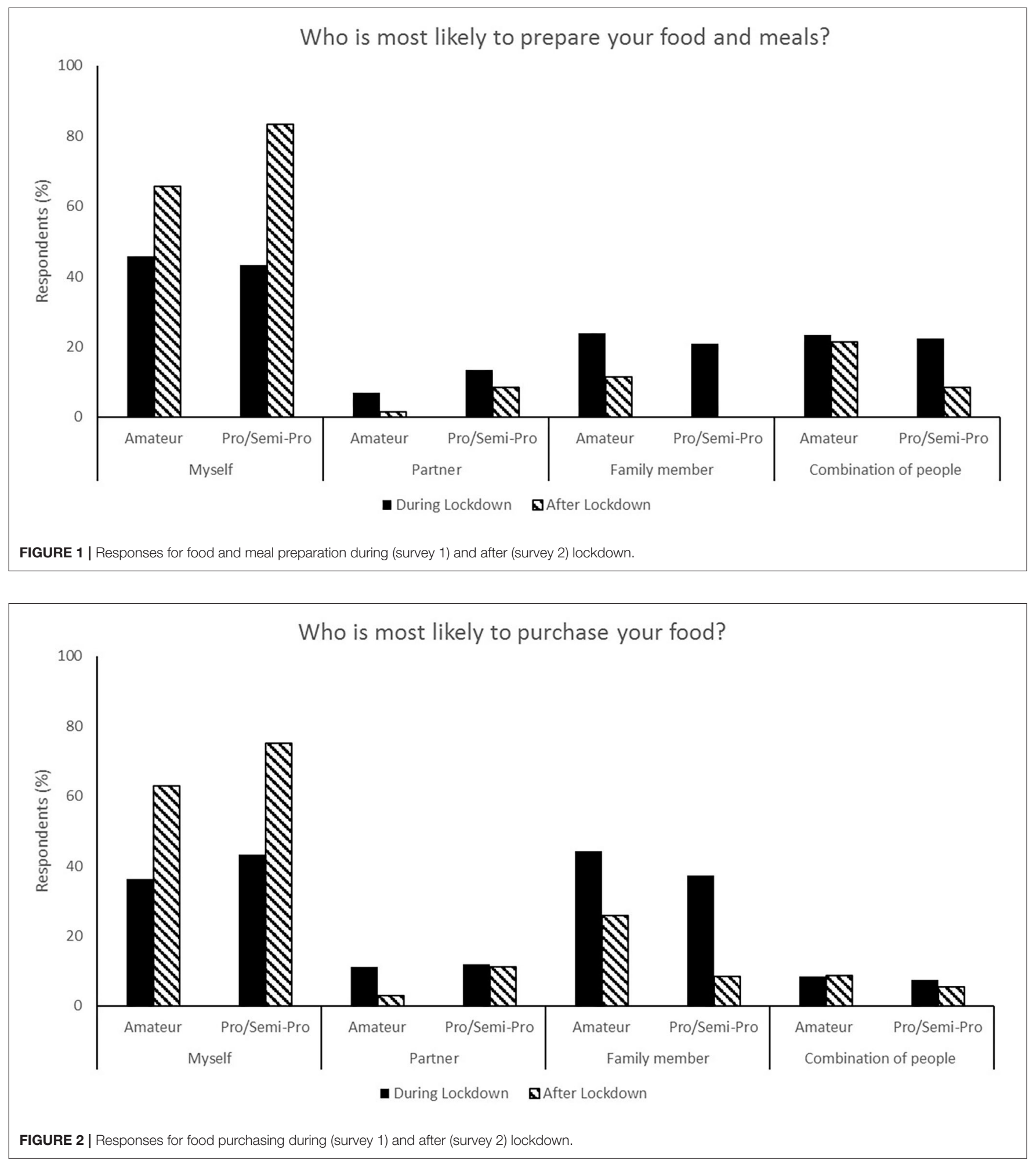

daily, this may be a useful strategy for athletes to minimize the detrimental effects of a reduction in training volume, a lack of appropriate equipment and limited rugby-specific training (6).

\section{Post-lockdown}

As many athletes appeared to return to the family home for the lockdown period, there would likely be a greater reliance and/or sharing of responsibilities surrounding nutrition. Following 

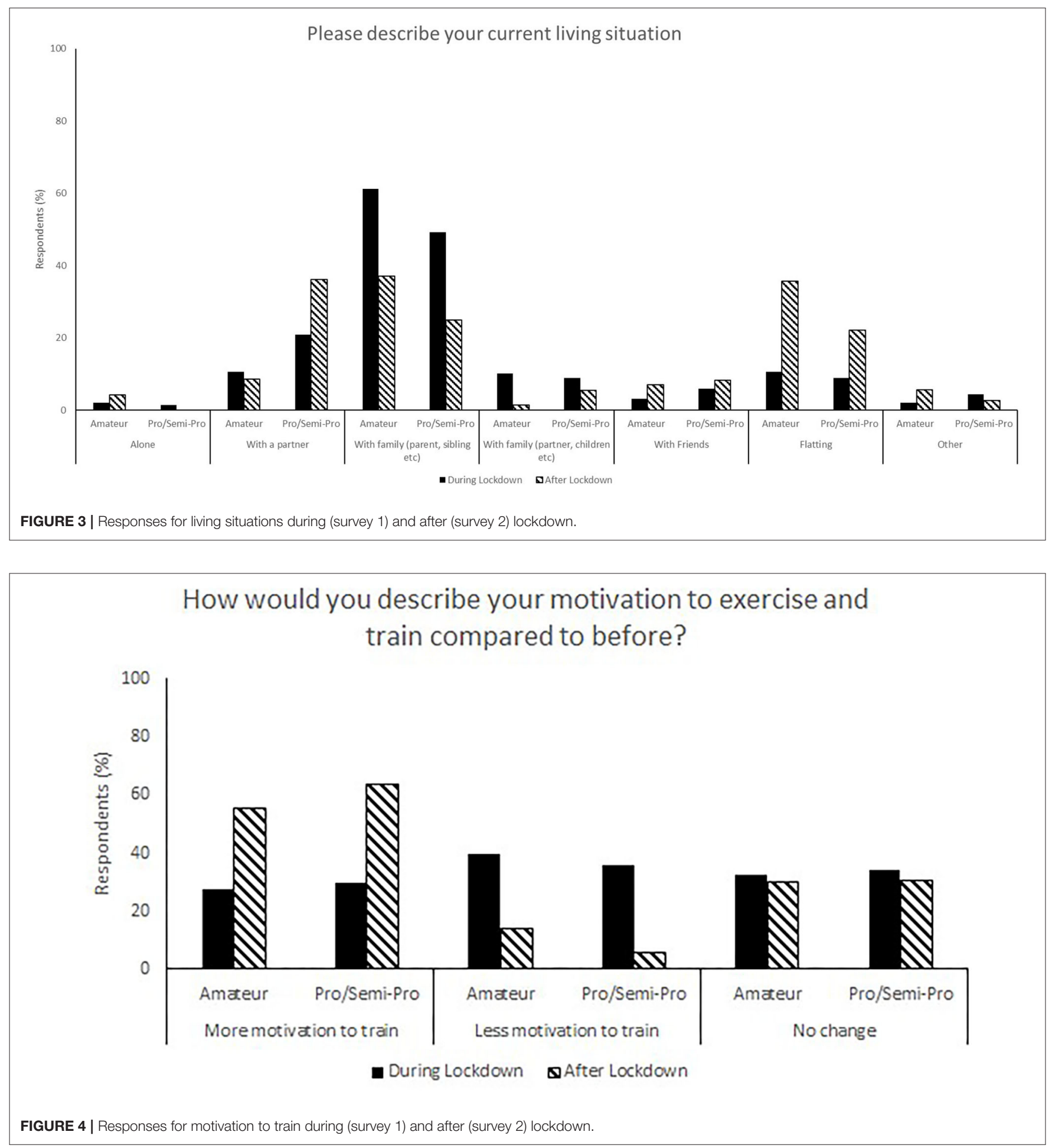

lockdown, those staying with family appeared to decrease and those flatting in shared accommodation increased. Therefore, there was a large shift in respondents indicating becoming more self-reliant, with a large number of athletes reporting purchasing their own food and preparing meals themselves. Reliance on others to prepare and cook meals can be a major barrier to healthy eating in athletes when those preparing meals do not possess appropriate sports nutrition knowledge. Furthermore, athletes cooking/shopping skills and cost can present further challenges in athletes at all levels of play (22). These factors should be considered by sports dieticians/nutritionists when aiming to improve athletes' nutrition knowledge and food intake. 


\section{When reflecting on total food intake, how would you describe your current food habits compared to before?}

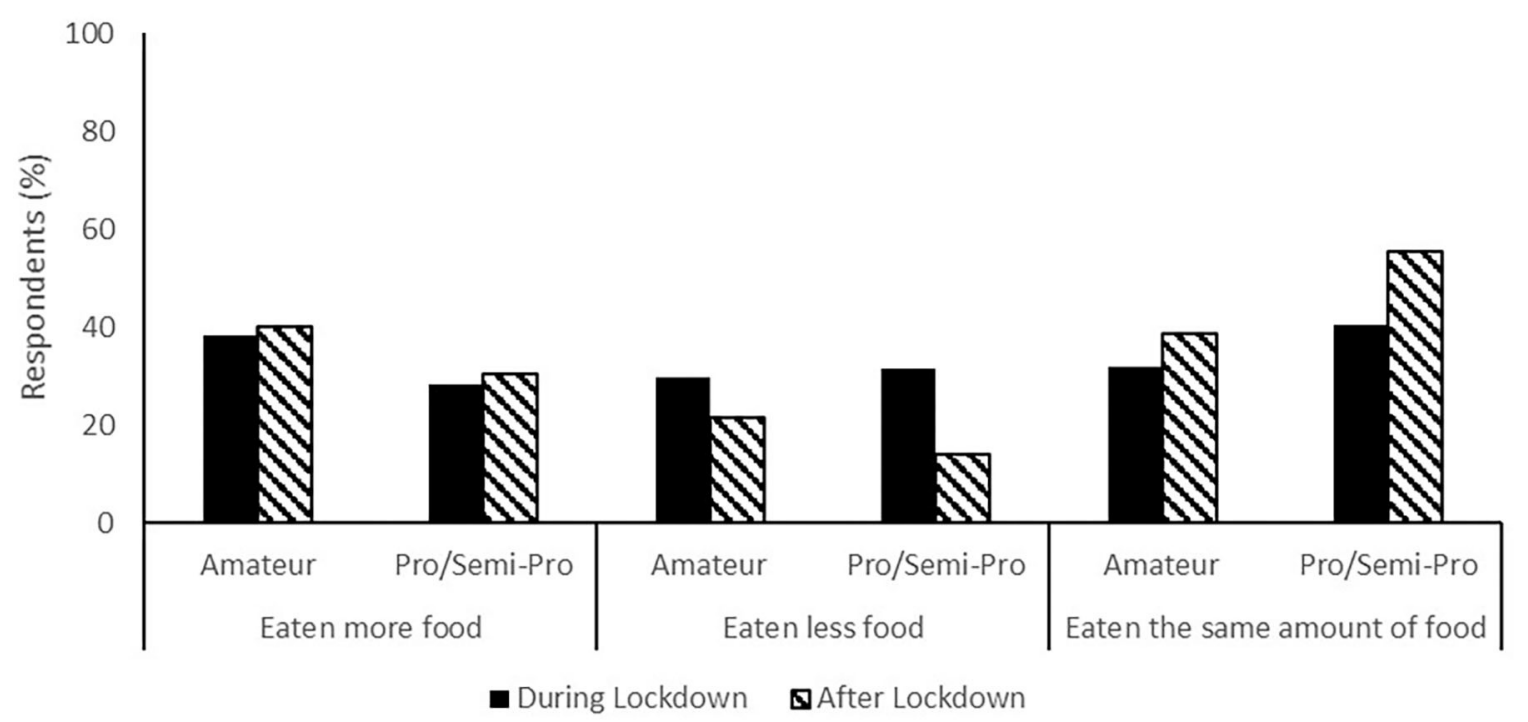

FIGURE 5 | Responses for total food intake during (survey 1) and after (survey 2) lockdown.

\section{How would you describe your current nutrition habits compared to before?}

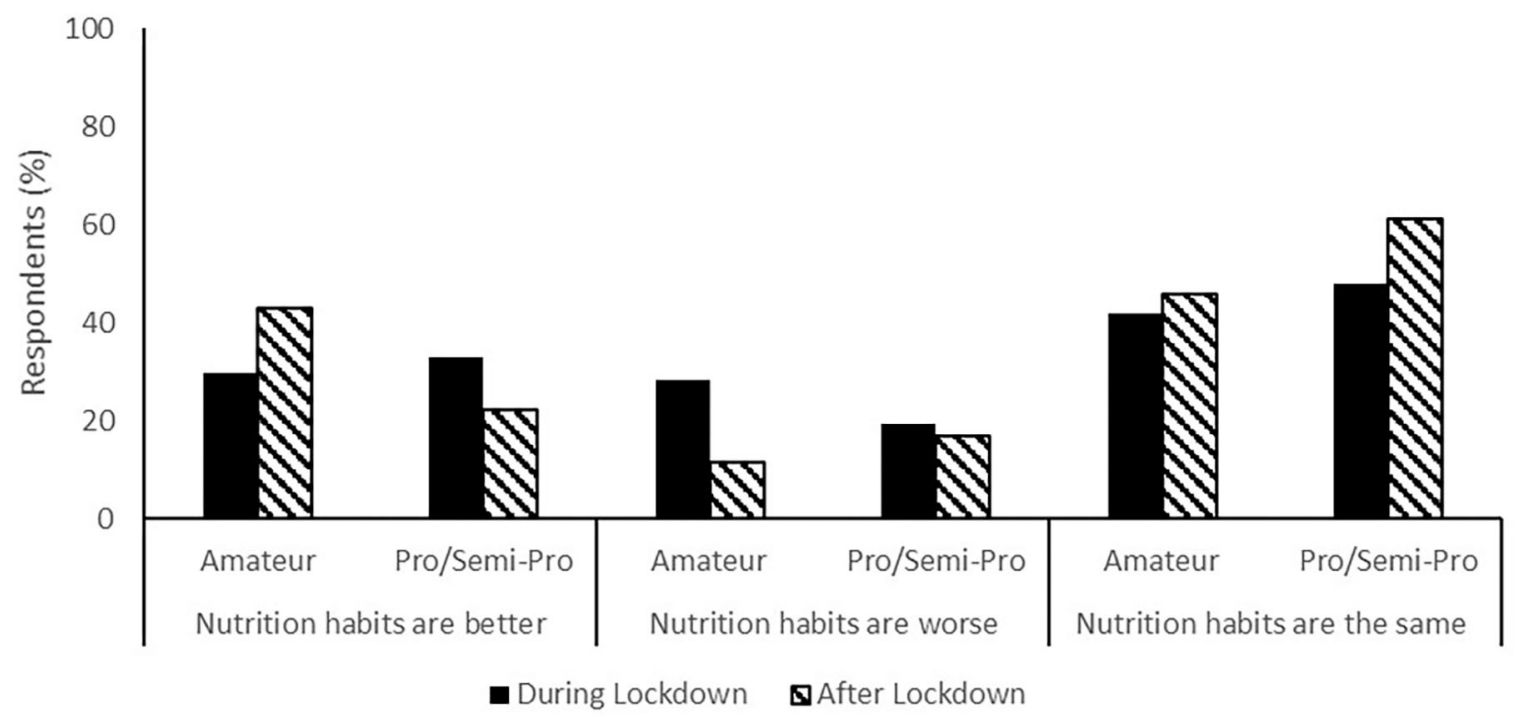

FIGURE 6 | Responses for nutrition habits during (survey 1) and after (survey 2) lockdown.

Sports nutrition knowledge in respondents from both surveys appeared to mainly come from dieticians or nutritionists associated with the clubs however a large number also reported other sources including other individuals (coaching staff, teammates, family members) or through seeking it themselves (internet, social media). Many coaches provide nutrition advice to athletes however these individuals do not often possess the appropriate level of knowledge required to do so (23). Teammates and family members who have not received appropriate training can provide incorrect and potentially 

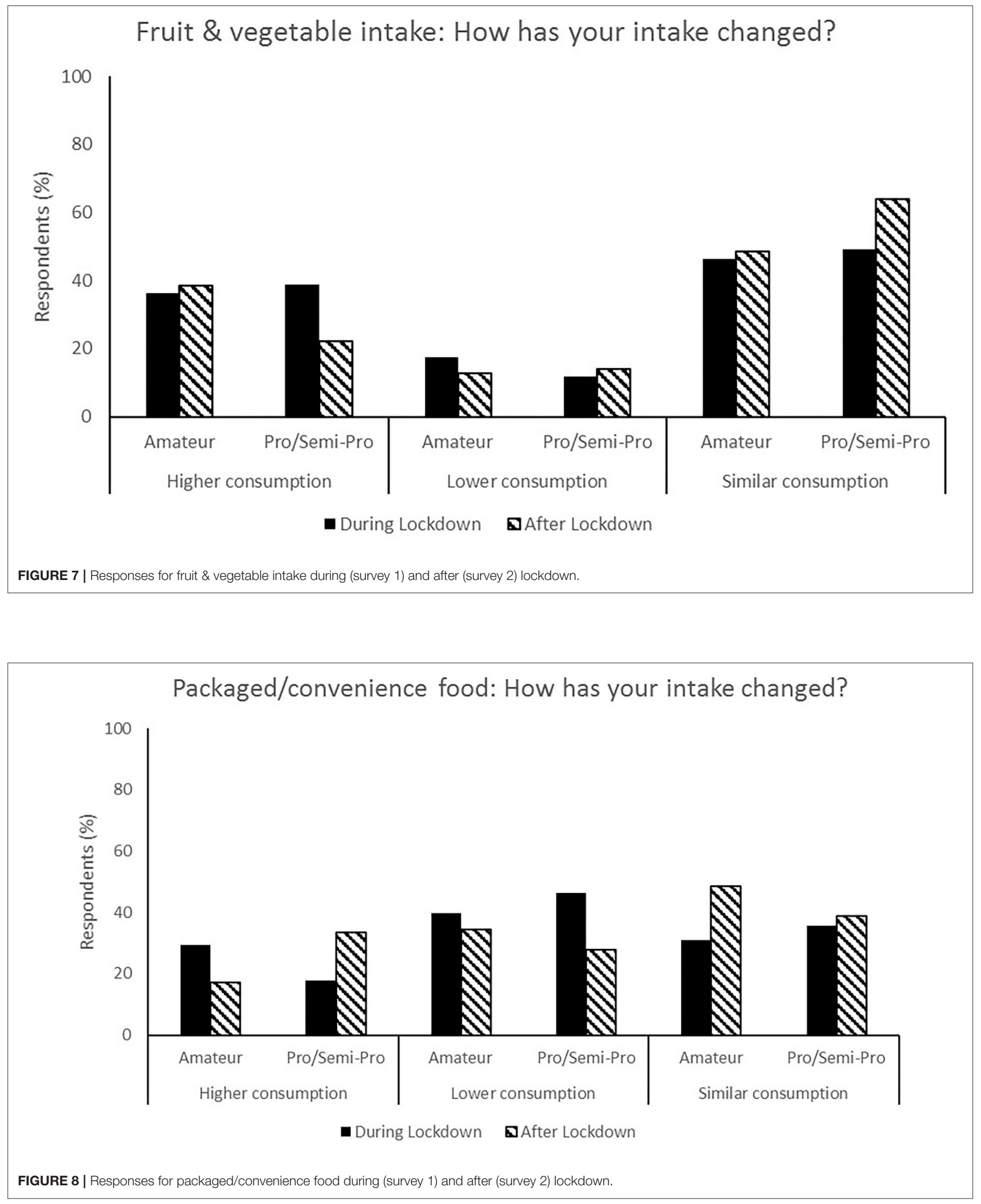
harmful information. Additionally, it is important that athletes are aware of the possibility of unreliable information being presented through digital channels (24).

Fast food outlets, cafes and takeaways were able to re-open following the relaxation of lockdown restrictions in New Zealand. A number of athletes reported eating out on $>3$ occasions weekly. Eating out can indeed be incorporated into an optimal diet for an athlete however it is important for these individuals to be aware of how to make appropriate choices. Increased frequency of fast-food consumption is associated with poorer diet quality, perhaps due to displacement of appropriate food choices (25). Less frequent food preparation and more frequent fast food consumption are associated with poorer diet quality, however time-restraints are a major influence on these factors (26). As most respondents identified as amateurs, it is likely these athletes also had full-time obligations in the form of work and/or studies. Furthermore, the social aspect of being involved in a team may outweigh focusing on eating for optimal performance, recovery and health in amateur athletes (27).

Unsurprisingly, most athletes indicated their motivation to exercise and train was higher once lockdown restrictions were relaxed. The physical and aggressive nature of the game, on and off-field interactions with teammates and feelings of achievement and success are some of the factors previously reported to increase participation motivation in elite female Rugby Union athletes (28). Lockdown restrictions would indeed cause major disruption to all of these factors. Additionally, the closure of habitual training facilities (clubhouses, gyms) and stressors associated with the pandemic are likely to have influenced athletes' motivation to train during lockdown.

Respondents of both Surveys 1 and 2 reported consuming high biological-value protein sources from whole foods less than once per day. These responses may indicate a lack of knowledge of the importance of regular protein consumption throughout the day for athletes. As with during lockdown, athletes concerned with maximizing lean mass and strength gains are recommended to consume a minimum of 1.6 g.kg.d spread evenly across at least 4 meals of 0.4 g.kg (29-31). Although athletes during lockdown will be experiencing different levels of exercise stimulation (lack of resistance training equipment, minimal rugby-specific training) which likely resulted in reductions in lean mass, strength and skill adequate protein consumption may allow for a faster return to pre-lockdown body composition and performance levels. Minimizing lean mass catabolism is also an important factor in reducing injury risk when Rugby Union training and match play resumes, with the development of the muscle tissue important for withstanding external forces associated with collision sport play (6).

\section{Limitations and Conclusion}

A major limitation of the present study is that the accuracy of the responses cannot be verified. Due to the anonymous nature of the online surveys distributed for this study, responses may not truly indicate how a respondent feels. Additionally, the nature of the questions means accurate results are difficult to obtain (for example, asking participants whether their food intake has changed as a result of lockdown measures) and information on macronutrient intake other than protein was not requested. Furthermore, respondents may not answer truthfully due to the additional stressors resulting from COVID19, such as economic struggles, feelings of isolation or health worries.

Participants were not asked to describe the nature of training sessions performed during lockdown, which presents another major limitation. It is likely that the implementation of lockdown measures would adversely affect resistance training and sportspecific training in athletes. With no access to commercial gym equipment, athletes are required to make use of limited equipment they may have at home or potentially none at all. If inadequate resistance training is performed, changes associated with muscle disuse such as lean mass and strength loss and increased fat mass may rapidly occur (32). It has been suggested that low-volume and low-intensity contractions are adequate at stimulating muscle protein synthesis and preventing muscle wasting (33). Resistance training protocols utilizing bands and bodyweight exercises have previously demonstrated efficacy in promoting lean mass gains in healthy older individuals (34) however this is not likely to be enough to maintain strength in Rugby Union athletes. Indeed, athletes are unlikely to have access to the equipment required to perform key exercises for developing or maintaining maximal strength (multijoint resistance exercises such as squats and deadlifts) (35) at sufficiently heavy loads ( $\geq 75 \%$ 1-repetition maximum) (36). For optimal performance and injury prevention, Rugby Union athletes are expected to possess high levels of strength and power whilst engaging in high metabolic training volumes and rugby-specific sessions (37) and re-building these attributes before competitive matches resume will be crucial. Most respondents indicated they completed at least three training sessions per week however no information was gathered as to the nature of these sessions and as such, the ability of the respondents to offset muscle disuse wasting cannot be predicted.

In conclusion, the COVID-19 pandemic and associated restrictions to encourage social distancing and delay the spread of the virus have presented significant challenges for athletes of all levels and disciplines. Appropriate nutritional and training support may assist athletes retain adequate performance, lean mass, strength and cardiorespiratory fitness during lockdown scenarios however no data is currently available to support this. Coaches and performance staff can assist athletes by promoting greater protein intakes and feeding frequency, encouraging safe supplement use and keeping players engaged in interesting training sessions that can be completed from home. Staff must also be aware of the challenges athletes may be facing, related or unrelated to the ongoing pandemic.

\section{DATA AVAILABILITY STATEMENT}

The raw data supporting the conclusions of this article will be made available by the authors, without undue reservation. 


\section{ETHICS STATEMENT}

Ethical review and approval was not required for the study on human participants in accordance with the local legislation and institutional requirements. The patients/participants provided their written informed consent to participate in this study.

\section{AUTHOR CONTRIBUTIONS}

CR, NG, and SS contributed to the development and distribution of the survey materials and edited the manuscript. CR drafted the

\section{REFERENCES}

1. World Health Organization. Timeline of WHO's Response to COVID-19. (2020). Available online at: https://www.who.int/news-room/detail/29-062020-covidtimeline (accessed July 15, 2020).

2. Mattioli AV, Ballerini Puviani M. Lifestyle at time of COVID-19: How could quarantine affect cardiovascular risk. Am J Lifestyle Med. (2020) 14:240-2. doi: 10.1177/1559827620918808

3. Pfefferbaum B, North CS. Mental health and the Covid-19 pandemic. New Engl J Med. (2020) 383:510-2. doi: 10.1056/NEJMp2008017

4. Dwyer MJ, Pasini M, De Dominicis S, Righi E. Physical activity: benefits and challenges during the COVID-19 pandemic. Scand J Med Sci Sports. (2020) 30:1291-4. doi: 10.1111/sms.13710

5. Deutsch MU, Kearney GA, Rehrer NJ. Time-motion analysis of professional rugby union players during match-play. J Sports Sci. (2007) 25:461-72. doi: 10.1080/02640410600631298

6. Stokes KA, Jones B, Bennett M, Close GL, Gill N, Hull JH, et al. Returning to play after prolonged training restrictions in professional collision sports. Int $J$ Sports Med. (2020). doi: 10.1055/a-1180-3692

7. Preedy VR, Watson RR, editors. Handbook of Disease Burdens and Quality of Life Measures. New York, NY: Springer (2010). p. 4189. doi: 10.1007/978-0-387-78665-0_5487

8. Gibson EL. Emotional influences on food choice: sensory, physiological and psychological pathways. Physiol Behav. (2006) 89:53-61. doi: 10.1016/j.physbeh.2006.01.024

9. Moreira CA, Bilezikian JP. Stress fractures: concepts and therapeutics. J Clin Endocrinol Metab. (2017) 102:525-34. doi: 10.1210/jc.2016-2720

10. Tipton KD. Nutritional support for exercise-induced injuries. Sports Med. (2015) 45:93-104. doi: 10.1007/s40279-015-0398-4

11. Close GL, Sale C, Baar K, Bermon S. Nutrition for the prevention and treatment of injuries in track and field athletes. Int J Sport Nutr Exerc Metab. (2019) 29:189-97. doi: 10.1123/ijsnem.2018-0290

12. Scarmozzino F, Visioli F. Covid-19 and the subsequent lockdown modified dietary habits of almost half the population in an Italian Sample. Foods. (2020) 9:675. doi: 10.3390/foods9050675

13. Sidor A, Rzymski P. Dietary choices and habits during COVID-19 lockdown: experience from Poland. Nutrients. (2020) 12:1657. doi: 10.3390/nu12061657

14. Narici M, De Vito G, Franchi M, Paoli A, Moro T, Marcolin G, et al. Impact of sedentarism due to the COVID-19 home confinement on neuromuscular, cardiovascular and metabolic health: physiological and pathophysiological implications and recommendations for physical and nutritional countermeasures. Eur J Sport Sci. (2020). doi: 10.1080/17461391.2020.1761076

15. Ammar A, Brach M, Trabelsi K, Chtourou H, Boukhris O, Masmoudi L, et al. Effects of COVID-19 home confinement on eating behaviour and physical activity: results of the ECLB-COVID19 International Online Survey. Nutrients. 12:1583. doi: 10.3390/nu12061583

16. Campbell B, Kreider RB, Ziegenfuss T, La Bounty P, Roberts M, Burke D, et al. International Society of Sports Nutrition position stand: protein and exercise. J Int Soc Sports Nutr. (2007) 4:8. doi: 10.1186/1550-2783-4-8 manuscript. All authors contributed to the article and approved the submitted version.

\section{ACKNOWLEDGMENTS}

The authors would like to acknowledge and thank all players who completed this survey.

\section{SUPPLEMENTARY MATERIAL}

The Supplementary Material for this article can be found online at: https://www.frontiersin.org/articles/10.3389/fnut.2020. 589737/full\#supplementary-material
17. Carbone JW, Pasiakos SM. Dietary protein and muscle mass: translating science to application and health benefit. Nutrients. (2019) 11:1136. doi: 10.3390/nu11051136

18. Knapik JJ, Steelman RA, Hoedebecke SS, Austin KG, Farina EK, Lieberman HR. Prevalence of dietary supplement use by athletes: systematic review and meta-analysis. Sports Med. (2016) 46:103-23. doi: 10.1007/s40279-015-0387-7

19. Maughan RJ, Depiesse F, Geyer H. The use of dietary supplements by athletes. J Sports Sci. (2007) 1:103-13. doi: 10.1080/02640410701607395

20. Maughan RJ, Shirreffs SM, Vernec A. Making decisions about supplement use. Int J Sport Nutr Exer Metab. (2018) 28:212-9. doi: 10.1123/ijsnem.2018-0009

21. Cintineo HP, Arent MA, Antonio J, Arent SM. Effects of protein supplementation on performance and recovery in resistance and endurance training. Front Nutr. (2018) 5:83. doi: 10.3389/fnut.2018.00083

22. Heaney S, O'Connor H, Naughton G, Gifford J. Towards an understanding of the barriers to good nutrition for elite athletes. Int J Sports Sci Coach. (2008) 3:391-401. doi: 10.1260/174795408786238542

23. Zinn C, Schofield G, Wall C. Evaluation of sports nutrition knowledge of New Zealand premier club rugby coaches. Int J Sport Nutr Exerc Metab. (2006) 16:214-25. doi: 10.1123/ijsnem.16.2.214

24. Bourke BE, Baker DF, Braakhuis AJ. Social media as a nutrition resource for athletes: a cross-sectional survey. Int J Sport Nutr Exerc Metab. (2019) 29:364-70. doi: 10.1123/ijsnem.2018-0135

25. Barnes TL, French SA, Mitchell NR, Wolfson J. Fast-food consumption, diet quality and body weight: cross-sectional and prospective associations in a community sample of working adults. Public Health Nutr. (2016) 19:885-92. doi: 10.1017/S1368980015001871

26. Larson NI, Perry CL, Story M, Neumark-Sztainer D. Food preparation by young adults is associated with better diet quality. J Am Diet Assoc. (2006) 106:2001-7. doi: 10.1016/j.jada.2006.09.008

27. Birkenhead KL, Slater G. A review of factors influencing athletes' food choices Sports Med. (2015) 45:1511-22. doi: 10.1007/s40279-015-0372-1

28. Kerr JH. The multifaceted nature of participation motivation in elite Canadian women rugby union players. Int J Sport Exerc Psychol. (2019) 3:1. doi: 10.1080/1612197X.2019.1611904

29. Schoenfeld BJ, Aragon AA. How much protein can the body use in a single meal for muscle-building? Implications for daily protein distribution. J Int Soc Sports Nutr. (2018) 15:10. doi: 10.1186/s12970-018-0215-1

30. Mamerow MM, Mettler JA, English KL, Casperson SL, Arentson-Lantz E, Sheffield-Moore M, et al. Dietary protein distribution positively influences 24-h muscle protein synthesis in healthy adults. J Nutr. (2014) 144:876-80. doi: 10.3945/jn. 113.185280

31. Areta JL, Burke LM, Ross ML, Camera DM, West DW, Broad EM, et al. Timing and distribution of protein ingestion during prolonged recovery from resistance exercise alters myofibrillar protein synthesis. J Physiol. (2013) 591:2319-31. doi: 10.1113/jphysiol.2012.244897

32. Wall BT, Snijders T, Senden JM, Ottenbros CL, Gijsen AP, Verdijk LB, et al. Disuse impairs the muscle protein synthetic response to protein ingestion in healthy men. J Clin Endocrinol Metab. (2013) 98:4872-81. doi: $10.1210 /$ jc. $2013-2098$ 
33. Glover EI, Phillips SM. Resistance exercise and appropriate nutrition to counteract muscle wasting and promote muscle hypertrophy. Curr Opin Clin Nutr Metabolic Care. (2010) 13:630-4. doi: 10.1097/MCO.0b013e32833 flae 5

34. Krause M, Crognale D, Cogan K, Contarelli S, Egan B, Newsholme P, et al. The effects of a combined bodyweight-based and elastic bands resistance training, with or without protein supplementation, on muscle mass, signaling and heat shock response in healthy older people. Exp Gerontol. (2019) 115:104-13. doi: 10.1016/j.exger.2018.12.004

35. Corcoran G, Bird S. Preseason strength training for rugby union: the general and specific preparatory phases. Strength Cond J. (2009) 31:66-74. doi: 10.1519/SSC.0b013e3181c225d9

36. Schoenfeld BJ, Ratamess NA, Peterson MD, Contreras B, Sonmez GT, Alvar BA. Effects of different volume-equated resistance training loading strategies on muscular adaptations in well-trained men. $J$
Strength Cond Res. (2014) 28:2909-18. doi: 10.1519/JSC.00000000000 00480

37. Gamble P. Physical preparation for elite-level rugby union football. Strength Cond J. (2004) 26:10-23. doi: 10.1519/00126548-200408000-00001

Conflict of Interest: The authors declare that the research was conducted in the absence of any commercial or financial relationships that could be construed as a potential conflict of interest.

Copyright (c) 2020 Roberts, Gill and Sims. This is an open-access article distributed under the terms of the Creative Commons Attribution License (CC BY). The use, distribution or reproduction in other forums is permitted, provided the original author(s) and the copyright owner(s) are credited and that the original publication in this journal is cited, in accordance with accepted academic practice. No use, distribution or reproduction is permitted which does not comply with these terms. 